\title{
Type 2 diabetes mellitus increases long-term mortality risk after isolated surgical aortic valve replacement
}

\author{
Eilon Ram ${ }^{1,3^{*+}} \oplus$ , Alexander Kogan ${ }^{1,2,3+}$, Shany Levin ${ }^{1}$, Enrique Z. Fisman ${ }^{3}$, Alexander Tenenbaum³ $^{3}$ \\ Ehud Raanani ${ }^{1,3}$ and Leonid Sternik ${ }^{1,3}$
}

\begin{abstract}
Background: Diabetes mellitus (DM) adversely affects morbidity and mortality for major atherosclerosis-related cardiovascular diseases and is associated with increased risk for the development of aortic stenosis. Clinical data regarding the impact of DM on outcomes of patients undergoing aortic valve replacement (AVR) have revealed inconsistent results. The aim of the current study was to investigate and compare the impact of type 2 DM on short-, intermediateand long-term mortality between DM and non-DM patients who undergo isolated AVR.

Methods: We performed an observational study in a large tertiary medical center over a 14-year period (2004-2018), which included all patients who had undergone isolated AVR surgery for the first time. Of the 1053 study patients, 346 patients (33\%) had type 2 DM (DM group) and were compared with non-DM (non-DM group) patients (67\%). Short-term (in-hospital), intermediate (1- and 3-years), and late (5- and 10-years) mortality were evaluated. Mean follow-up of was 69 \pm 43 months.

Results: Short-term (in-hospital) mortality was similar between the DM compared with the non-DM group: 3.5\% and $2.5 \%(p=0.517)$. Intermediate-term mortality ( 1 - and 3-year) was higher in the DM group compared with the non-DM group, but did not reach statistical significance: $8.1 \%$ vs. $5.7 \%(p=0.169)$ and $12.1 \%$ vs. $8.3 \%(p=0.064)$ respectively. Long-term (5- and 10-year) mortality was significantly higher in the DM group, compared to the non-DM group: $19.4 \%$ vs. $12.9 \%(p=0.007)$ and $30.3 \%$ vs. $23.5 \%(p=0.020)$ respectively. Among the $346 \mathrm{DM}$ patients, $55(16 \%)$ were treated with insulin and 291 (84\%) with oral antiglycemic medication only. Overall in-hospital mortality among insulin-treated DM patients was $7.3 \%$ compared with $2.7 \%$ among non insulin-treated DM patients $(p=0.201)$. Longterm mortality was higher in the subgroup of insulin-treated DM patients compared with the subgroup of non-insulin treated DM patients with an overall mortality rate of $36.4 \% \mathrm{vs.} 29.2 \%(p=0.039)$. Furthermore, predictors for late mortality included DM (HR 1.39 Cl 1.03-1.86, $p=0.031)$ and insulin treatment ( $\mathrm{HR} 1.76 \mathrm{Cl} 1.05-2.94, \mathrm{p}=0.033)$, as demonstrated after adjustment for confounders by multivariable analysis.
\end{abstract}

Conclusions: Type $2 \mathrm{DM}$ is an independent predictor for long-term mortality after isolated AVR surgery.

Keywords: Diabetes mellitus, Aortic valve replacement, Insulin

\section{Introduction}

Aortic valve stenosis (AS), the most commonly acquired valve disorder, is emerging as a new epidemic in the western world due to ageing populations [1].

\footnotetext{
*Correspondence: eilon.ram@sheba.health.gov.il

†Eilon Ram and Alexander Kogan contributed equally to this paper

${ }^{3}$ Sheba Medical Center, Tel Hashomer, Affiliated to the Sackler School

of Medicine, Tel Aviv University, Tel Aviv, Israel

Full list of author information is available at the end of the article
}

Diabetes mellitus (DM) adversely affects morbidity and mortality for major atherosclerosis-related cardiovascular diseases [2]. Following cardiac surgery and particularly coronary artery bypass surgery, patients with DM have been shown to suffer higher rates of adverse events including higher mortality rates [3-5]. Furthermore, DM is associated with increased risk for the development of AS [6, 7], and was found to be the second most significant factor 
associated with AS after hypertension [8]. Aortic valves from diabetic patients with AS who require valve replacement have shown more calcification, with a higher grade of mineralization than non-diabetic patients [9].

Clinical data regarding the impact of DM on outcomes of patients undergoing aortic valve replacement (AVR) have revealed inconsistent results $[10,11]$. The aim of the current study was to investigate and compare the impact of type 2 DM on short-, intermediate- and longterm mortality between DM and non-DM patients who undergo isolated AVR for the first time.

\section{Methods}

\section{Study design and population}

We performed a retrospective, observational study that included prospectively-collected data from a large tertiary university hospital. Between 01.09.2004 and 31.06.2018 a total of 1053 patients underwent their first isolated AVR. Of them 346 (33\%) suffered from type 2 DM (DM group) and 707 (67\%) had no DM (nonDM group). DM type 2 was defined according to the American Diabetes Association as: (a) hemoglobin $\mathrm{A} 1 \mathrm{C} \geq 6.5 \%$; (b) fasting plasma glucose levels $\geq 126 \mathrm{mg} /$ $\mathrm{dL}(7 \mathrm{mmol} / \mathrm{L})$; (c) classic symptoms of hyperglycemia or a hyperglycemic crisis, a random plasma glucose level $\geq 200 \mathrm{mg} / \mathrm{dL}$ (11.1 mmol/L) [12]; or (d) currently on pharmacologic treatment (oral antihyperglycemic drugs and/or insulin). The results of the 346 diabetic patients (55 with and 291 without insulin therapy) were analyzed by the use of insulin treatment. The study was approved by the Sheba Medical Center Institutional Ethics Committee (Protocol No 4257). The requirement for informed consent was waived because of the retrospective nature of the study.

\section{Surgical procedures and postoperative care}

Standard cardiopulmonary bypass was established by cannulation of the ascending aorta and the right atrium or the right femoral artery and vein. Myocardial protection was achieved by using antegrade and/or retrograde cold blood cardioplegia.

After surgery all patients were admitted to the intensive care unit (ICU) directly from the operating room. Following discharge from the ICU, patients were transferred either to a step-down unit or directly to the floor, from where they were discharged either to their home or to a rehabilitation facility. In the operating room and in the ICU, patients from both the DM and non-DM groups received intravenous continuous infusion of regular insulin according to the Society of Thoracic Surgeons practice guideline series [13]. After discharge from the ICU, the
non-DM patients received no insulin nor any other hypoglycemic medication, while the DM patients continued to receive preoperative antiglycemic treatment (per oral drugs and insulin), as soon as they began to eat.

\section{Data collection and follow-up}

All hospital data were ascertained by hospital chart review, telephone contact, and clinical follow-up. Data included: demographic parameters, medical history, chronic and peri-procedural medical treatment, echocardiography measurements, procedural information, and outcome measures. Mortality data were ascertained from the Israeli Ministry of Interior, Population Register through November 2018. Mean follow-up was $69 \pm 43$ months and was completed for $98 \%$ of the patients.

\section{Statistical analysis}

Data are presented as mean \pm standard deviation. Continuous variables were tested with the Kolmogorov-Smirnov test for normal distribution. Categorical variables are given as frequencies and percentages. A Chi square test was used for comparison of categorical variables between the DM and non-DM groups and between oral antihyperglycemic-treated and insulin-treated DM patients. A Student's t-test was performed for comparison of normally distributed continuous variables and Mann-Whitney U test for non-normal distribution.

Cox regression analysis was used to identify factors associated with long-term mortality adjusted to patient's age. Candidate covariates are provided in Table 1. A Cox proportional hazard model was constructed to assess the association between DM and long-term mortality. Variables that were associated with long-term mortality adjusted to age were included in the regression model. In addition, we included pre-specified clinically significant variables in the model. The variables included in the final model were: age, gender, peripheral vascular disease, chronic obstructive pulmonary disease, New York Heart Association functional class III-IV and hyperlipidemia. In addition, Kaplan-Meier survival analysis was performed to compare long-term mortality among the subgroup of DM patients, with statistical differences tested by the log-rank test.

Statistical significance was assumed when the null hypothesis could be rejected at $\mathrm{p}<0.05$. All $\mathrm{p}$-values are the results of two-sided tests. Statistical analyses were conducted using R (version 3.4.1) [14].

\section{Results}

\section{Baseline characteristics}

During the 14-year study period, 1053 patients underwent isolated AVR and were included in the study. There 
Table 1 Patient characteristics

\begin{tabular}{|c|c|c|c|c|c|}
\hline & \multicolumn{2}{|l|}{ Diabetes $(\mathrm{N}=346)$} & \multirow{2}{*}{$\begin{array}{l}\text { Non-diabetes } \\
(\mathrm{N}=707)\end{array}$} & \multirow{2}{*}{$\begin{array}{l}\text { p-value } \\
\text { Insulin vs. non- } \\
\text { insulin }\end{array}$} & \multirow{2}{*}{$\begin{array}{l}\text { p-value } \\
\text { DM vs. non-DM }\end{array}$} \\
\hline & $\begin{array}{l}\text { Insulin treatment } \\
(\mathrm{N}=55)\end{array}$ & $\begin{array}{l}\text { Non-insulin treatment } \\
(\mathrm{N}=291)\end{array}$ & & & \\
\hline Age (years) & $69 \pm 8$ & $70 \pm 10$ & $67 \pm 14$ & 0.339 & $<0.001$ \\
\hline Gender (male) & $30(55 \%)$ & $161(55 \%)$ & 361 (51\%) & 1.000 & 0.240 \\
\hline Hypertension & $50(91 \%)$ & $257(88 \%)$ & $447(63 \%)$ & 0.745 & $<0.001$ \\
\hline Previous MI & $8(15 \%)$ & $30(10 \%)$ & $51(7 \%)$ & 0.493 & 0.052 \\
\hline COPD & $12(22 \%)$ & $33(11 \%)$ & $49(7 \%)$ & 0.057 & 0.002 \\
\hline Dialysis & $3(6 \%)$ & $5(2 \%)$ & $8(1 \%)$ & 0.229 & 0.229 \\
\hline Hyperlipidemia & 50 (91\%) & $240(83 \%)$ & $382(54 \%)$ & 0.174 & $<0.001$ \\
\hline Smoking & $8(15 \%)$ & $79(27 \%)$ & $115(16 \%)$ & 0.071 & 0.001 \\
\hline PVD & $6(11 \%)$ & $23(8 \%)$ & $28(4 \%)$ & 0.637 & 0.005 \\
\hline Prior CVA/TIA & $3(6 \%)$ & $23(8 \%)$ & $50(7 \%)$ & 0.724 & 0.894 \\
\hline Neurological deficit & $2(4 \%)$ & $7(2 \%)$ & $18(2 \%)$ & 0.949 & 1.000 \\
\hline Atrial fibrillation & $5(9 \%)$ & $12(4 \%)$ & $38(5 \%)$ & 0.221 & 0.866 \\
\hline BMI (mean) & $37 \pm 47$ & $32 \pm 32$ & $28 \pm 14$ & 0.345 & 0.004 \\
\hline Obesity & $23(42 \%)$ & $109(38 \%)$ & 147 (21\%) & 0.646 & $<0.001$ \\
\hline Standard EuroSCORE I & $7.9 \pm 12.6$ & $5.9 \pm 2.6$ & $5.6 \pm 2.6$ & 0.021 & 0.022 \\
\hline NYHA FC III-IV & $30(55 \%)$ & $115(40 \%)$ & $240(35 \%)$ & 0.072 & 0.029 \\
\hline Ejection fraction (\%) & $55 \pm 12$ & $56 \pm 11$ & $57 \pm 11$ & 0.341 & 0.125 \\
\hline Pulmonary hypertension & $7(13 \%)$ & $16(6 \%)$ & $31(4 \%)$ & 0.093 & 0.157 \\
\hline Bicuspid aortic valve & $5(9 \%)$ & $32(11 \%)$ & $109(15 \%)$ & 0.856 & 0.047 \\
\hline
\end{tabular}

DM Diabetes mellitus, $M I$ myocardial dysfunction, COPD chronic obstruction pulmonary disease, PVD peripheral vascular disease, CVA cerebral vascular accident, TIA transient ischemic attack, $B M I$ body mass index, NYHA FC New York Heart Association functional class

were 707 patients $(67 \%)$ in the non-DM group and 346 patients (33\%) in the DM group (Table 1). Of them, 291 patients $(84 \%)$ were treated with oral antihyperglycemic medications and 55 patients (16\%) were treated with insulin (Table 1). Compared with the non-DM group, the DM group had significantly more co-morbidities as shown in Table 1. Operative date was similar between the DM and non-DM groups (Table 2).

\section{Surgical procedures}

A median sternotomy approach was performed in 897 patients (85.2\%); a partial sternotomy (J-sternotomy) was performed on 126 patients (12\%), and a right minithoracotomy on 30 patients (2.8\%). 938 patients $(89 \%)$ received a biological prosthesis and 115 (11\%) a mechanical prosthesis.

\section{Mortality}

Short-term (in-hospital) mortality was similar between the DM compared with the non-DM patients: $3.5 \%$ vs. $2.5 \%, \mathrm{p}=0.517$. While overall intermediate-term mortality (1- and 3-year) were somewhat higher in the DM compared with the non-DM patients, it did not reach statistical significance: $8.1 \%$ vs. $5.7 \%, \mathrm{p}=0.169 ; 12.1 \%$ vs. $8.3 \%, \mathrm{p}=0.064$; respectively.

Comparison between DM and non-DM patients regarding late mortality revealed a significant long-term advantage in favor of the non-DM patients (Fig. 1). The 5- and 10-year mortality rates were higher in patients with, compared to those without DM: $19.4 \%$ vs. $12.9 \%$, $\mathrm{p}=0.007$ and $30.3 \%$ vs. $23.5 \%, \mathrm{p}=0.020$; respectively (Table 3 and Fig. 1).

Multivariable analysis demonstrated that predictors for late mortality include DM $(\mathrm{p}=0.031)$, older age, with $7 \%$ increased odds for mortality per 1-year increment in age $(p<0.001)$, chronic obstructive pulmonary disease $(p=0.008)$, and lower ejection fraction $(p=0.003)$ (Table 4).

\section{Subgroup analysis}

Among the 346 DM patients, 55 (16\%) were treated with insulin and 291 (84\%) with oral antiglycemic medication only (Table 1). Overall in-hospital mortality among insulin-treated DM patients was 7.3\% compared with $2.7 \%$ among non insulin-treated DM patients $(\mathrm{p}=0.201)$. Intermediate-term (1- and 3-year) mortality was higher in the insulin-treated DM group compared with the non insulin-treated DM group, but did not reach statistical 
Table 2 Operative data

\begin{tabular}{|c|c|c|c|}
\hline & $\begin{array}{l}\text { Diabetes } \\
(N=346)\end{array}$ & $\begin{array}{l}\text { Non-diabetes } \\
(\mathrm{N}=707)\end{array}$ & $\mathrm{p}$-value \\
\hline Minimally invasive & & & 0.218 \\
\hline Mid-sternotomy & $286(83 \%)$ & $611(86 \%)$ & \\
\hline J-sternotomy & $50(14 \%)$ & $76(11 \%)$ & \\
\hline Right mini-thoracotomy & $10(3 \%)$ & $20(3 \%)$ & \\
\hline Valve prosthesis & & & 0.084 \\
\hline Biological & $317(92 \%)$ & $621(88 \%)$ & \\
\hline Mechanical & $29(8 \%)$ & $86(12 \%)$ & \\
\hline Valve size & & & 0.237 \\
\hline 18 & $1(0.3 \%)$ & $1(0.1 \%)$ & \\
\hline 19 & $24(7 \%)$ & $58(8.3 \%)$ & \\
\hline 20 & $8(2.3 \%)$ & $20(2.9 \%)$ & \\
\hline 21 & $120(35.1 \%)$ & $232(33.2 \%)$ & \\
\hline 22 & $14(4.1 \%)$ & $26(3.7 \%)$ & \\
\hline 23 & 97 (28.4\%) & $148(21.2 \%)$ & \\
\hline 24 & $13(3.8 \%)$ & $29(4.1 \%)$ & \\
\hline 25 & $37(10.8 \%)$ & $125(17.9 \%)$ & \\
\hline 26 & $7(2 \%)$ & $14(2 \%)$ & \\
\hline 27 & $16(4.7 \%)$ & $38(5.4 \%)$ & \\
\hline 28 & $1(0.3 \%)$ & $2(0.3 \%)$ & \\
\hline 29 & $4(1.2 \%)$ & $5(0.7 \%)$ & \\
\hline 33 & $0(0 \%)$ & $1(0.1 \%)$ & \\
\hline Cross-clamp time (min) & $63 \pm 20$ & $64 \pm 45$ & 0.761 \\
\hline $\begin{array}{l}\text { Cardiopulmonary bypass time } \\
\text { (min) }\end{array}$ & $115 \pm 44$ & $114 \pm 44$ & 0.715 \\
\hline Total operative time (min) & $229 \pm 50$ & $226 \pm 48$ & 0.361 \\
\hline
\end{tabular}

significance: $12.7 \%$ vs. $7.2 \%(\mathrm{p}=0.269)$ and $16.4 \%$ vs. $11.3 \%(\mathrm{p}=0.412)$ respectively.

Furthermore, long-term mortality was higher in the subgroup of insulin-treated DM patients compared with the subgroup of non-insulin treated DM patients with an overall mortality rate of $36.4 \%$ vs. $29.2 \%(p=0.039$, Fig. 2). Among the DM patients, predictors for late mortality were insulin treatment (HR 1.76 95\% CI 1.05-2.94, $\mathrm{p}=0.033$ ), older age, with $6 \%$ increased odds for mortality per 1 -year increment in age $(\mathrm{p}<0.001)$, and chronic obstructive pulmonary disease (HR 1.89 95\% CI 1.12$3.19, \mathrm{p}=0.018)$.

\section{Discussion}

This study, carried out in a contemporary cohort of patients who underwent their first isolated AVR, demonstrates several important implications regarding the impact of type $2 \mathrm{DM}$ on in-hospital, mid- and long-term mortality. We have shown that long-term mortality was higher in DM patients than in non-DM patients, and that mortality rate was affected by the diabetic treatment strategy with worse outcomes in patients treated with insulin as compared with patients not treated with insulin.

While the impact of diabetes on short-term mortality after AVR remains controversial, DM has been included in the Society of Thoracic Surgeons (STS) risk score [15] as a marker of poor prognosis after cardiac surgery. EuroSCORE II is a very good predictor of in-hospital mortality after cardiac surgery and can be safely be used for quality assurance and risk assessment [16] and insulintreated DM has been specifically included in it [17]. Both the STS score and the EuroSCORE II were validated to predict 30 -day mortality after cardiac surgery $[15,17]$. López-de-Andrés et al. [18] reported a significantly lower in-hospital mortality rate among DM patients (3.9-8.9\%) than among non-DM patients $(5.1-7.8 \%)(\mathrm{p}<0.001)$, and Abramowitz et al. [19] reported a lower 30-day mortality rate among DM compared with non-DM patients (5\% vs. $5.9 \%, \mathrm{p}<0.001$ ), while Linke et al. [20] found no differences in 30-day mortality between DM and non-DM patients: $6.2 \%$ vs. $7.5 \%$. Anyway, data are controversial since DM has been found to be significantly and consistently associated to higher in-hospital mortality in a huge Spanish population after major cardiovascular events [21], and also Mendez-Bailon et al. [22] reported a lower in-hospital mortality rate in patients with, compared to those without DM $(4.4 \%$ vs. $6.3 \%, \mathrm{p}<0.01)$. About a third of our study patients were diabetic, with 55 of them (16\%) receiving insulin treatment.

We report here that in-hospital mortality among DM and non-DM patients, was $3.5 \%$ and $2.5 \%$. In the noninsulin $(\mathrm{N}=291)$ compared with the insulin-treated $(\mathrm{N}=55)$ subgroup of patients, in-hospital mortality was $2.7 \%$ and $7.3 \%, p=0.201$. While our findings were not statistically significant, the difference reported by us could be clinically relevant. Whereas our small sample size was underpowered to reach conclusive results, a larger cohort might have shown significantly higher early mortalities among DM patients, particularly in those on insulin therapy.

However, the impact of diabetes on mid- and long-term mortality after isolated AVR surgery has been consistent in several reports. Linke et al. [20] found significantly higher 1- and 3-year mortality rates between DM and non-DM patients: $21.6 \%$ vs. $20.5 \%(\mathrm{p}=0.02)$ and $33.4 \%$ vs. $28.4 \%(\mathrm{p}<0.01)$. A post hoc analysis of the PARTNER trial, stratified according to the DM status of patients randomly assigned to undergo AVR, revealed a 1-year mortality rate of $27.4 \%$ in DM patients and $23.7 \%$ in non-DM patients [23]. At 1-year, Abramowitz et al. [19] reported that DM was significantly associated with a higher mortality hazard (HR $1.395 \%$ CI 1.13-1.49, p<0.001). This association was stronger among insulin-treated patients (HR 1.57 95\% CI 1.28-1.91, $\mathrm{p}<0.001$ ). We report here the 


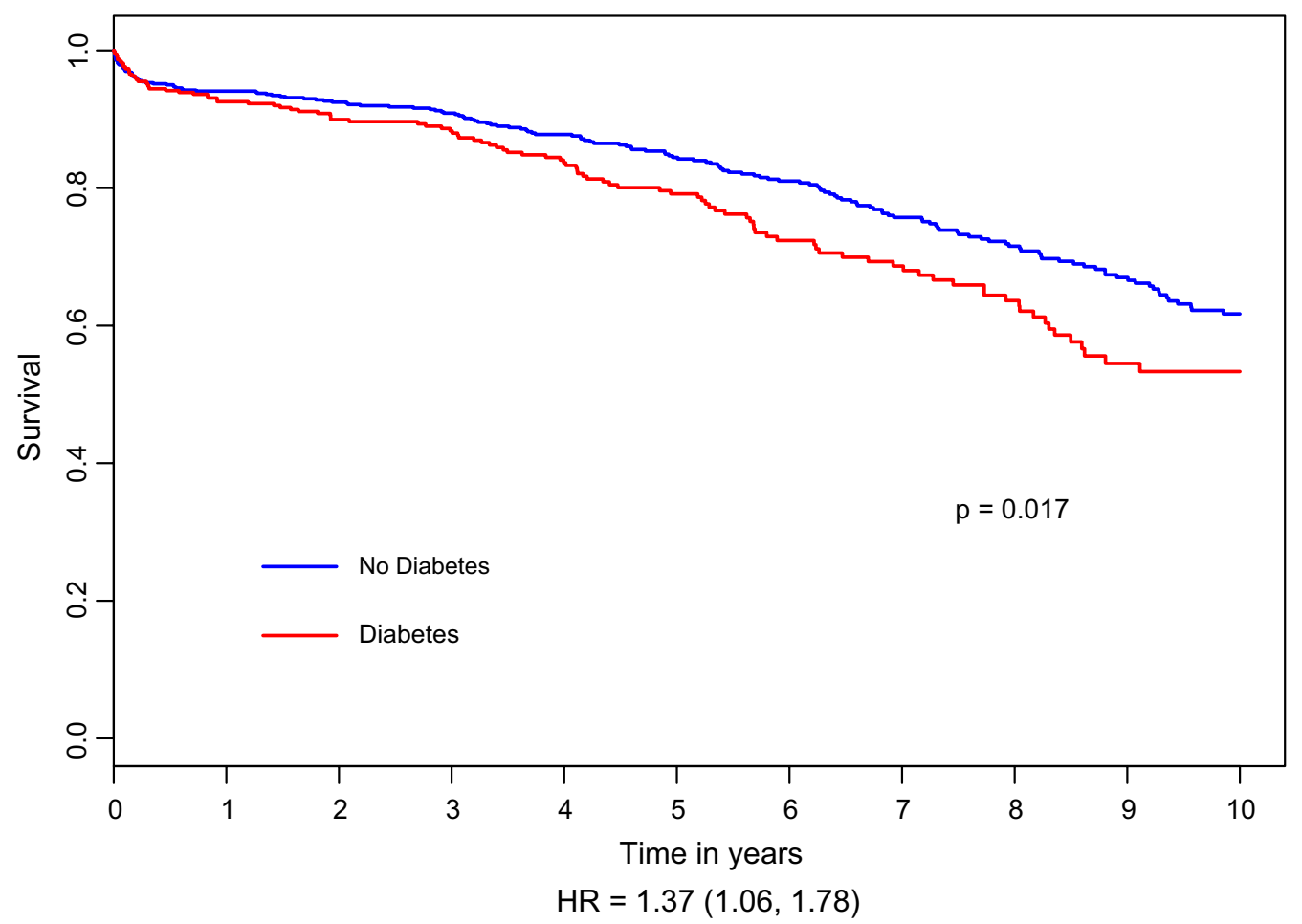

Fig. 1 Hazard plot for survival at 10-year by the presence of diabetes mellitus, with propensity score adjustment. The covariates included in the model were: age, gender, PVD, COPD, NYHA functional class III-IV and hyperlipidemia. HR Hazard ratio, PVD peripheral vascular disease, COPD chronic obstruction pulmonary disease, NYHA New York Heart Association

Table 3 Hazard ratios for mortality at 1-, 3-, 5-, and 10-years, adjusted for age

\begin{tabular}{|c|c|c|c|c|c|c|c|c|c|c|c|c|}
\hline & \multicolumn{3}{|c|}{ 1-year } & \multicolumn{3}{|c|}{ 3-year } & \multicolumn{3}{|c|}{ 5-year } & \multicolumn{3}{|c|}{ 10-year } \\
\hline & $H R$ & $95 \% \mathrm{Cl}$ & p-value & $\mathrm{HR}$ & $95 \% \mathrm{Cl}$ & p-value & $H R$ & $95 \% \mathrm{Cl}$ & p-value & HR & $95 \% \mathrm{Cl}$ & $p$-value \\
\hline Diabetes & 1.33 & $0.82-2.15$ & 0.250 & 1.37 & $0.92-2.04$ & 0.117 & 1.47 & $1.07-2.01$ & 0.018 & 1.44 & $1.12-1.84$ & 0.004 \\
\hline Gender (male) & 1.51 & $0.93-2.45$ & 0.097 & 1.55 & $1.04-2.32$ & 0.031 & 1.31 & $0.96-1.79$ & 0.093 & 1.12 & $0.88-1.43$ & 0.348 \\
\hline Obesity & 0.72 & $0.39-1.32$ & 0.288 & 0.92 & $0.58-1.45$ & 0.713 & 0.87 & $0.59-1.26$ & 0.454 & 0.95 & $0.72-1.26$ & 0.737 \\
\hline Hypertension & 0.67 & $0.4-1.12$ & 0.129 & 0.67 & $0.44-1.03$ & 0.068 & 0.83 & $0.57-1.19$ & 0.307 & 0.91 & $0.68-1.21$ & 0.521 \\
\hline PVD & 2.45 & $1.21-4.95$ & 0.013 & 2.90 & $1.67-5.02$ & 0.000 & 2.58 & $1.61-4.14$ & 0.000 & 2.08 & $1.4-3.07$ & 0.000 \\
\hline Previous MI & 1.61 & $0.82-3.17$ & 0.168 & 1.53 & $0.87-2.7$ & 0.143 & 1.32 & $0.82-2.11$ & 0.253 & 1.19 & $0.82-1.71$ & 0.356 \\
\hline Hyperlipidemia & 0.49 & $0.3-0.79$ & 0.004 & 0.63 & $0.42-0.93$ & 0.022 & 0.69 & $0.5-0.95$ & 0.024 & 0.79 & $0.62-1.01$ & 0.059 \\
\hline Smoking & 0.59 & $0.29-1.18$ & 0.137 & 0.95 & $0.58-1.56$ & 0.850 & 0.9 & $0.6-1.34$ & 0.602 & 0.96 & $0.71-1.31$ & 0.812 \\
\hline COPD & 2.05 & $1.07-3.9$ & 0.030 & 2.18 & $1.3-3.68$ & 0.004 & 2.46 & $1.62-3.72$ & 0.000 & 2.42 & $1.72-3.41$ & 0.000 \\
\hline NYHA FC III-IV & 1.23 & $0.76-2$ & 0.393 & 1.24 & $0.83-1.84$ & 0.289 & 1.32 & $0.96-1.81$ & 0.086 & 1.28 & $1.01-1.64$ & 0.045 \\
\hline Ejection fraction & 0.96 & $0.95-0.98$ & 0.000 & 0.97 & $0.95-0.98$ & 0.000 & 0.97 & $0.96-0.99$ & 0.000 & 0.98 & $0.97-0.99$ & 0.000 \\
\hline
\end{tabular}

PVD peripheral vascular disease, MI myocardial dysfunction, COPD chronic obstruction pulmonary disease, NYHA FC New York Heart Association functional class

results of a longer follow-up period than previously published, with a mean follow-up of $69 \pm 43$ months, demonstrating consistent results toward a worse rate of survival among DM patients, particularly those receiving insulin.

Diabetes mellitus is one of the major causes of heart failure in patients with reduced ejection fraction [24], and even in cases in which ejection fraction is preserved $[25,26]$. In general, insulin-treated DM patients have more co-morbidities than non insulin-treated DM patients $[5,27,28]$ and are prone to more revascularization procedures $[16,29]$. The presence of insulin treatment as a marker for more rapid prosthetic 
Table 4 Cox regression analysis

\begin{tabular}{|c|c|c|c|c|c|c|}
\hline & \multicolumn{3}{|c|}{ Univariable analysis } & \multicolumn{3}{|c|}{ Multivariable analysis } \\
\hline & HR & $\mathrm{Cl}$ & p-value & $\mathrm{HR}$ & $\mathrm{Cl}$ & p-value \\
\hline Age & 1.08 & $1.06-1.09$ & $<0.001$ & 1.07 & $1.06-1.09$ & $<0.001$ \\
\hline Diabetes & 1.55 & $1.21-1.97$ & $<0.001$ & 1.39 & $1.03-1.86$ & 0.031 \\
\hline PVD & 2.36 & $1.6-3.49$ & $<0.001$ & 1.35 & $0.81-2.25$ & 0.252 \\
\hline COPD & 2.19 & $1.57-3.05$ & $<0.001$ & 1.89 & $1.19-3.02$ & 0.008 \\
\hline NYHA FC III-IV & 1.53 & $1.2-1.93$ & $<0.001$ & 1.03 & $0.76-1.39$ & 0.846 \\
\hline Ejection fraction & 0.98 & $0.96-0.99$ & $<0.001$ & 0.98 & $0.97-0.99$ & 0.003 \\
\hline
\end{tabular}

Predictors for late mortality by univariable and multivariable analysis

PVD Peripheral vascular disease, COPD chronic obstruction pulmonary disease, NYHA FC New York Heart Association functional class, HR hazard ratio, Cl confidence interval

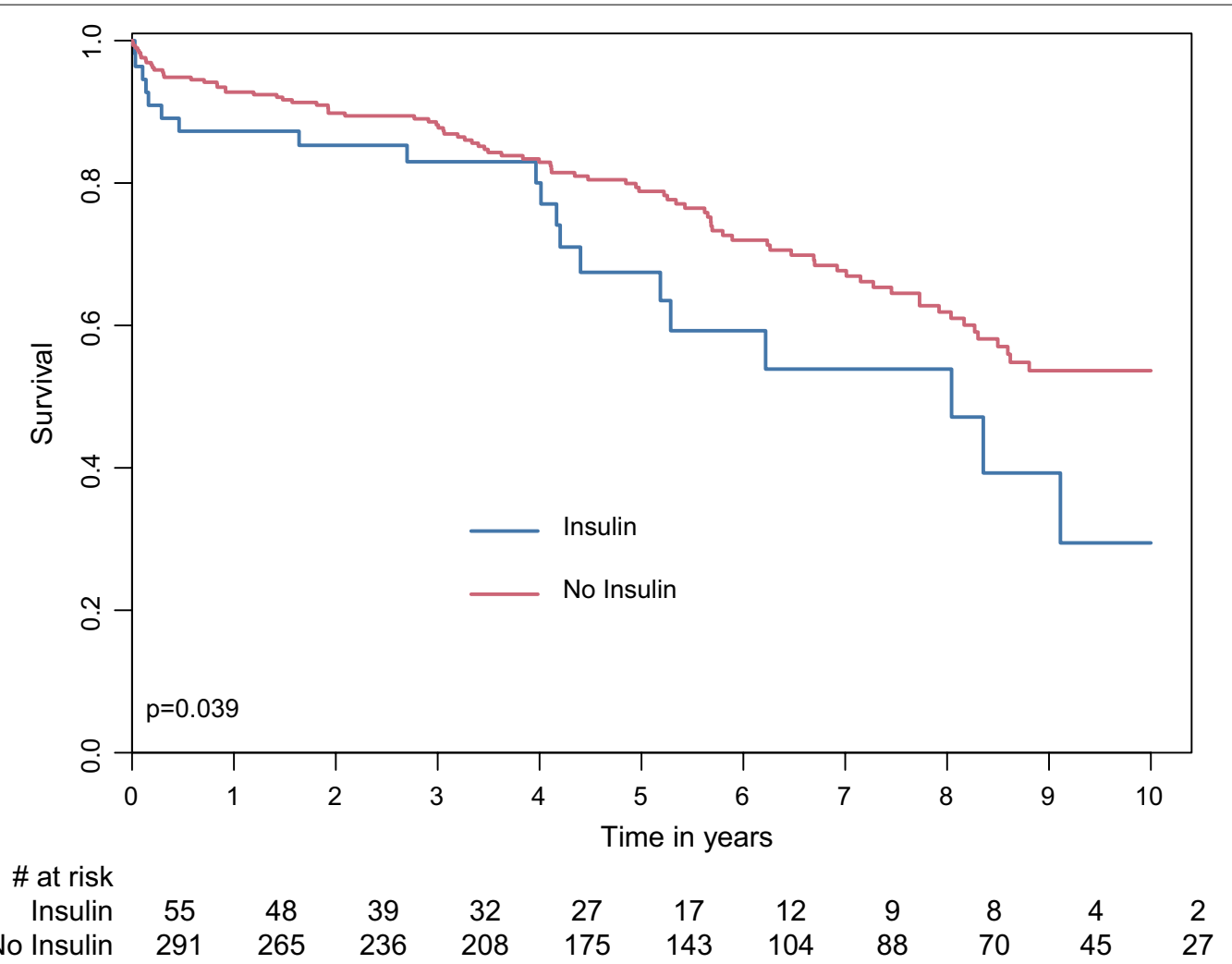

Fig. 2 Survival rate in the DM group by insulin treatment. DM Diabetes mellitus

valve deterioration remains debatable. Furthermore, its underlying biological mechanism has not yet been fully elucidated. Insulin may be related to the impact of a procoagulant imbalance, chronic exposure to high glucose levels, and direct effects of hyperinsulinemia. Further studies are needed to examine whether insulintreated DM patients should be included in risk stratification algorithms for patients who undergo first-time AVR.
Aortic valve replacement and transcatheter aortic valve implantation (TAVI) are the only effective treatments for severe AS. Currently, however, TAVI is limited to moderate-high risk patients only, when the risk of TAVI is estimated to be lower than the risk of AVR, taking into consideration the fact that long-term results of TAVI are still unknown [30]. While we and others have reported that DM is a significant risk factor for late mortality after AVR [10], long-term mortality after TAVI for DM patients still needs further investigation. 
Among the entire cohort of patients in our study who underwent isolated AVR, those with DM were older. One could surmise that, as in ischemic heart disease, DM patients present with less symptoms and therefore tend to be diagnosed later, resulting in treatment delays. However, we believe that this is not the case in DM AVR patients. Compared with DM patients, non-DM patients in our study had a significantly higher presence of bicuspid aortic valve, that tended to deteriorate at a higher rate, and therefore were operated on at an earlier stage of disease progression. We have shown that mortality was affected by the presence of DM regardless of patient age. While in the general population type $2 \mathrm{DM}$ is associated with excess mortality compared with those without DM, with a HR of 1.15 at 5 years [31], we report here that DM had a greater impact on patients who underwent firsttime isolated AVR (HR of 1.58 at 5 years).

\section{Limitations}

There are a few limitations in our study. First, despite it being retrospective in design, data were collected prospectively and recorded in a well-defined database. Second, our study was conducted in a single-center cardiac surgery department. Third, we had no information regarding the main cause of death, the rate of cardiac events and data regarding prosthetic valve performance during the follow-up period. Analysis of cardiac events could reinforce the conclusion that DM provides less favorable results after AVR. The lack of information regarding the main cause of death weakens the conclusions of this study.

\section{Conclusions}

Type-2 DM is an independent predictor of long-term (5- and 10-years) mortality after AVR. Mortality rates increased significantly when the diabetic treatment strategy included insulin. A larger study is required in order to examine weather DM has an impact on early mortality.

\section{Abbreviations}

AS: aortic valve stenosis; AVR: aortic valve replacement; DM: diabetes mellitus; ICU: intensive care unit; TAVI: transcatheter aortic valve implantation.

\section{Authors' contributions}

ER: wrote the research project and the full manuscript. AK, LS: wrote the research project and study revision. SL: data collection and interpretation. EZF, AT: study revision and editing. ER: study revision. All authors read and approved the final manuscript.

\section{Author details}

${ }^{1}$ Department of Cardiac Surgery, Tel Aviv University, Tel Aviv, Israel. ${ }^{2}$ Cardiac Surgery Intensive Care Unit, Tel Aviv University, Tel Aviv, Israel. ${ }^{3}$ Sheba Medical Center, Tel Hashomer, Affiliated to the Sackler School of Medicine, Tel Aviv University, Tel Aviv, Israel.
Acknowledgements

Not applicable.

Competing interests

The authors declare that they have no competing interests.

Availability of data and materials

Data collected from a departmental database.

Consent for publication

Not applicable.

Ethics approval and consent to participate

Institutional Ethical Committee (Protocol No 4257).

Funding

None.

\section{Publisher's Note}

Springer Nature remains neutral with regard to jurisdictional claims in published maps and institutional affiliations.

Received: 16 February 2019 Accepted: 1 March 2019

Published online: 15 March 2019

\section{References}

1. lung B, Baron G, Butchart EG, Delahaye F, Gohlke-Barwolf C, Levang $\mathrm{OW}$, et al. A prospective survey of patients with valvular heart disease in Europe: the Euro Heart Survey on Valvular Heart Disease. Eur Heart J. 2003;24:1231-43.

2. Shah AD, Langenberg C, Rapsomaniki E, Denaxas S, Pujades-Rodriguez M, Gale CP, et al. Type 2 diabetes and incidence of a wide range of cardiovascular diseases: a cohort study in 1.9 million people. Lancet. 2015;385(Suppl 1):S86.

3. Bucerius J, Gummert JF, Walther T, Doll N, Falk V, Onnasch JF, et al. Impact of diabetes mellitus on cardiac surgery outcome. Thorac Cardiovasc Surg. 2003:51:11-6.

4. Al-Khabori M, Al-Riyami AZ, Mukaddirov M, Al-Sabti H. Transfusion indication predictive score: a proposed risk stratification score for perioperative red blood cell transfusion in cardiac surgery. Vox Sang. 2014;107:269-75.

5. Kogan A, Ram E, Levin S, Fisman EZ, Tenenbaum A, Raanani E, et al. Impact of type 2 diabetes mellitus on short- and long-term mortality after coronary artery bypass surgery. Cardiovasc Diabetol. 2018;17:151.

6. Larsson SC, Wallin A, Hakansson N, Stackelberg O, Back M, Wolk A. Type 1 and type 2 diabetes mellitus and incidence of seven cardiovascular diseases. Int J Cardiol. 2018;262:66-70.

7. Falcao-Pires I, Hamdani N, Borbely A, Gavina C, Schalkwijk CG, van der Velden J, et al. Diabetes mellitus worsens diastolic left ventricular dysfunction in aortic stenosis through altered myocardial structure and cardiomyocyte stiffness. Circulation. 2011;124:1151-9.

8. Yan AT, Koh M, Chan KK, Guo H, Alter DA, Austin PC, et al. Association between cardiovascular risk factors and aortic stenosis: the CANHEART Aortic Stenosis Study. J Am Coll Cardiol. 2017;69:1523-32.

9. Mosch J, Gleissner CA, Body S, Aikawa E. Histopathological assessment of calcification and inflammation of calcific aortic valves from patients with and without diabetes mellitus. Histol Histopathol. 2017;32:293-306.

10. Halkos ME, Kilgo P, Lattouf OM, Puskas JD, Cooper WA, Guyton RA, et al. The effect of diabetes mellitus on in-hospital and long-term outcomes after heart valve operations. Ann Thorac Surg. 2010;90:124-30.

11. Berkovitch A, Segev A, Barbash I, Grossman Y, Maor E, Erez A, et al. Clinical impact of diabetes mellitus in patients undergoing transcatheter aortic valve replacement. Cardiovasc Diabetol. 2015;14:131.

12. Association AD. Classification and diagnosis of diabetes. Diabetes Care. 2015:38(Suppl):S8-16.

13. Lazar HL, McDonnell M, Chipkin SR, Furnary AP, Engelman RM, Sadhu AR, et al. The Society of Thoracic Surgeons practice guideline series: blood glucose management during adult cardiac surgery. Ann Thorac Surg. 2009:87:663-9. 
14. Team RDC. R: a language and environment for statistical computing. Vienna: Team RDC; 2015

15. Anderson RP. First publications from the Society of Thoracic Surgeons National Database. Ann Thorac Surg. 1994;57:6-7

16. Orbach A, Halon DA, Jaffe R, Rubinshtein R, Karkabi B, Flugelman MY, et al. Impact of diabetes and early revascularization on the need for late and repeat procedures. Cardiovasc Diabetol. 2018;17:25.

17. Nashef SA, Roques F, Michel P, Gauducheau E, Lemeshow S, Salamon R. European system for cardiac operative risk evaluation (EuroSCORE). Eur J Cardiothorac Surg. 1999;16:9-13.

18. Lopez-de-Andres A, Perez-Farinos N, de Miguel-Diez J, HernandezBarrera V, Mendez-Bailon M, de Miguel-Yanes JM, et al. Impact of type 2 diabetes mellitus in the utilization and in-hospital outcomes of surgical aortic valve replacement in Spain (2001-2015). Cardiovasc Diabetol. 2018;17:135.

19. Abramowitz Y, Vemulapalli S, Chakravarty T, Li Z, Kapadia S, Holmes D, et al. Clinical impact of diabetes mellitus on outcomes after transcatheter aortic valve replacement: insights from the Society of Thoracic Surgeons/ American College of Cardiology Transcatheter Valve Therapy Registry. Circ Cardiovasc Interv. 2017:10:e005417.

20. Linke A, Schlotter F, Haussig S, Woitek FJ, Stachel G, Adam J, et al. Genderdependent association of diabetes mellitus with mortality in patients undergoing transcatheter aortic valve replacement. Clin Res Cardiol. 2018:108:39-47.

21. de Miguel-Yanes JM, Jimenez-Garcia R, Hernandez-Barrera V, MendezBailon M, de Miguel-Diez J, Lopez-de-Andres A. Impact of type 2 diabetes mellitus on in-hospital-mortality after major cardiovascular events in Spain (2002-2014). Cardiovasc Diabetol. 2017;16:126.

22. Mendez-Bailon M, Lorenzo-Villalba N, Munoz-Rivas N, de Miguel-Yanes JM, De Miguel-Diez J, Comin-Colet J, et al. Transcatheter aortic valve implantation and surgical aortic valve replacement among hospitalized patients with and without type 2 diabetes mellitus in Spain (2014-2015). Cardiovasc Diabetol. 2017;16:144.

23. Lindman BR, Pibarot P, Arnold SV, Suri RM, McAndrew TC, Maniar HS, et al. Transcatheter versus surgical aortic valve replacement in patients with diabetes and severe aortic stenosis at high risk for surgery: an analysis of the PARTNER Trial (Placement of Aortic Transcatheter Valve). J Am Coll Cardiol. 2014:63:1090-9.
24. Gu J, Pan JA, Fan YQ, Zhang HL, Zhang JF, Wang CQ. Prognostic impact of $\mathrm{HbA} 1 \mathrm{c}$ variability on long-term outcomes in patients with heart failure and type 2 diabetes mellitus. Cardiovasc Diabetol. 2018;17:96.

25. Meagher P, Adam M, Civitarese R, Bugyei-Twum A, Connelly KA. Heart failure with preserved ejection fraction in diabetes: mechanisms and management. Can J Cardiol. 2018;34:632-43.

26. Huynh T, Harty BJ, Claggett B, Fleg JL, MCKinlay SM, Anand IS, et al. Comparison of outcomes in patients with diabetes mellitus treated with versus without insulin + heart failure with preserved left ventricular ejection fraction (from the TOPCAT study). Am J Cardiol. 2019;123:611-7.

27. Rossello X, Ferreira JP, McMurray JJ, Aguilar D, Pfeffer MA, Pitt B, et al. Impact of insulin-treated diabetes on cardiovascular outcomes following high-risk myocardial infarction. Eur Heart J Acute Cardiovasc Care. 2018. https://doi.org/10.1177/2048872618803701.

28. Brixner D, Ermakova A, Xiong Y, Sieradzan R, Sacks N, Cyr P, et al. Clinical and economic outcomes patients with type 2 diabetes on multiple daily injections of Basal-Bolus Insulin (MDI) therapy: a retrospective cohort study. Clin Ther. 2019. https://doi.org/10.1016/j.clinthera.2018.12.014.

29. Bundhun PK, Li N, Chen MH. Adverse cardiovascular outcomes between insulin-treated and non-insulin treated diabetic patients after percutaneous coronary intervention: a systematic review and meta-analysis. Cardiovasc Diabetol. 2015;14:135.

30. Bonow RO, Brown AS, Gillam LD, Kapadia SR, Kavinsky CJ, Lindman BR, et al. ACC/AATS/AHA/ASE/EACTS/HVS/SCA/SCAI/SCCT/SCMR/STS 2017 appropriate use criteria for the treatment of patients with severe aortic stenosis: a report of the American College of Cardiology Appropriate Use Criteria Task Force, American Association for Thoracic Surgery, American Heart Association, American Society of Echocardiography, European Association for Cardio-Thoracic Surgery, Heart Valve Society, Society of Cardiovascular Anesthesiologists, Society for Cardiovascular Angiography and Interventions, Society of Cardiovascular Computed Tomography, Society for Cardiovascular Magnetic Resonance, and Society of Thoracic Surgeons. J Am Coll Cardiol. 2017;70:2566-98.

31. Tancredi M, Rosengren A, Svensson AM, Kosiborod M, Pivodic A, Gudbjornsdottir $\mathrm{S}$, et al. Excess mortality among persons with type 2 diabetes. N Engl J Med. 2015;373:1720-32.
Ready to submit your research? Choose BMC and benefit from:

- fast, convenient online submission

- thorough peer review by experienced researchers in your field

- rapid publication on acceptance

- support for research data, including large and complex data types

- gold Open Access which fosters wider collaboration and increased citations

- maximum visibility for your research: over $100 \mathrm{M}$ website views per year

At $\mathrm{BMC}$, research is always in progress.

Learn more biomedcentral.com/submissions 